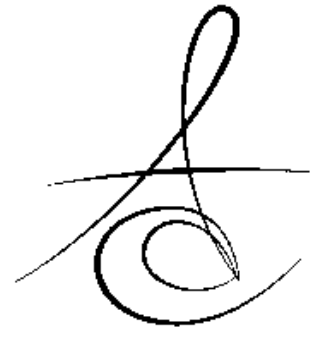

Yrd. Doç. Dr. Emre BAYRAM

Yrd. Doç. Dr. Necla DEMİR**

\section{FARKLI APİKAL AÇIKLIĞA SAHİP DİŞLERDE İNTERNAL MATRİX İLE BİRLİKTE KULLANILAN MTA'NIN APİKAL SIZINTISININ DEĞERLENDİRİLMESİ}

\section{EVALUATION OF APICAL LEAKAGE OF DIFFERENT APICAL DIAMETER TEETH USED MTA COMBINED WITH INTERNAL MATRIX}

\author{
Yrd. Doç. Dr. Hüda Melike BAYRAM*
}

Arş. Gör. Elif Sümeyye TOBİ**

Makale Kodu/Article code: 2276

Makale Gönderilme tarihi; 22.05 .2015

Kabul Tarihi: 28.09.2015

\section{öz}

Amaç: Bu çalışmanın amacı, farklı apikal çaplara sahip $(1 \mathrm{~mm}$ ve $1.4 \mathrm{~mm})$ immatur dişlere ortograd ve retrograd yollarla, farklı uygulama teknikleri ile yerleştirdiğimiz MTA'nın apikal sızıntılarının bilgisayarlı SIVı filtrasyon tekniği ile belirlenmesidir.

Gereç ve yöntem: Çalışmada kullanmak için toplamda 100 adet çekilmiş üst çene keser insan dişi kullanıldı. Açık apekse sahip immatür dişleri simüle etmek amacıyla apikal foramen, çapı $1 \mathrm{~mm}$ ve $1.4 \mathrm{~mm}$ genişliğinde olacak şekilde prepare edildi. Üretici firmanın talimatları doğrultusunda karıştırılan MTA dört farklı yolla (retrograd yolla, ortograd yolla, 2 aşamalı ortograd yolla ve internal matrix destekli ortograd yolla) farklı apikal foramen çapa sahip kök kanallarının içerisine yerleştirildi.

Dişler bilgisayarlı sıvı-filtrasyon cihazında mikrosızıntı testi için hazırlandı. Sızıntı çalışmasındaki her bir örnekteki sıvı hareketi ölçümleri 15 saniye aralıklarla 8 kez tekrarlandı ve bu ölçümlerin ortalama değerleri kaydedildi [ $\mu \mathrm{l} /(\mathrm{dk} * \mathrm{cmH} 2 \mathrm{O} * \mathrm{~cm} 2)$ ]. Sızıntı deneylerinden elde edilen verilerin istatistiksel analizinde SPSS 20 programı kullanıldı.

Bulgular: Elde edilen veriler tek yönlü ANOVA ve post-hoc Tukey testleri kullanılarak analiz edildi. Gruplar arasında istatistiksel fark bulundu. En az sızıntı internal matrix in $1 \mathrm{~mm}$ genişlikte ortograt uygulanan grupta görüldü. En fazla sızıntı ise $1.4 \mathrm{~mm}$ açıklığa sahip dişlerde retrograt uygulamada gözlendi. MTA'nın internal matrix ile birlikte kullanıldığı gruplarda ve MTA'nın iki aşamalı yerleştirildiği gruplarda sızıntı miktarı MTA'nın tek seferde yerleştirildiği gruplardan daha azdır.

Sonuç: Çalışmamızda uyguladığımı ortograt prosedürde internal matrix ile birlikte MTA uygulandığında apikal sızıntı değerleri en azdır. Klinik olarak bu metodun tercih edildiği durumlarda, cerrahi uygulama sayıları azaltılabilir ve daha az invaziv uygulamalarla tedaviler yapılabilir.

Anahtar Kelimeler: İmmatür diş, Mikrosızıntı, MTA, SIVı filtrasyon

\section{ABSTRACT}

Aim The aim of this study is to determine the effect of apical foramen diameter, and different application methods on the sealing ability of MTA using computerized fluid filtration device.

Material and methods: 100 extracted human teeth were used for this study. In our study, apical foramen were prepared diameter of $1-1.4 \mathrm{~mm}$ in width for to simulate the open apex with an immature teeth. MTA was mixed according to manufacturer's recommendations, and was placed into the root canals which have a different apical foramen diameter. by four different ways (retrograde way, two-phased ortograde way, and ortograde with or without internal matrix way).

The teeth were prepared for the microleakage test with computerise fluid-filtration method. Measurements of fluid movement were made at intervals of 15 -seconds and repeated 8 times and means of these measurements were recorded [ $\mu \mathrm{l} /$ $\left.\left(\min * \mathrm{cmH}_{2} \mathrm{O} * \mathrm{~cm}^{2}\right)\right]$.

SPSS 20 software was used for statistical analysis of apical leakage of data. The data was analysed with one-way ANOVA and post-hoc Tukey tests.

Results: The amount of leakage in groups the internal matrix used together with MTA and two stages arranged MTA are less than the group placed one step MTA.

Conclusion: In our study, less apical leakage was determined in performed ortograde procedure with internal matrix. When this method is prefered clinically, the cases can be treated by less invasive application and reducing the number of surgery.

Key words: fluid filtration, immature tooth, leakage, MTA

\footnotetext{
*Gaziosmanpaşa Üniversitesi, Diş Hekimliği Fakültesi, Endodonti A.D.
}

**Selçuk Üniversitesi, Diş Hekimliği Fakültesi, Protez A.D 


\section{GİRİŞ}

Travma, çürük veya diğer pulpa patolojileri sebebiyle kök gelişimini tamamlamamış dişler özel bir dikkat ve tedavi gerektirmektedir. Canlılığını kaybetmiş ve kök ucu oluşumunu tamamlamamış dişler, ince ve kırılgan dentin duvarları ile geniş kök kanalları ve apikal açıklığa sebep olması sebebiyle endodontik tedavi için her zaman sorun oluşturmuştur. ${ }^{1,2}$

Bu tip dişlerin, kök kanal duvarlarının kalınlığı azalmış olduğundan az miktarda dentin uzaklaştııılmakta bu durum da biyomekanik preparasyonu sınırlamaktadır. ${ }^{3}$ Ayrıca, apikalde bir sert doku engeli oluşmadığı için, kök kanallarının apikal ve lateral yönde sızdırmaz bir şekilde doldurulması oldukça zordur. ${ }^{4}$ Bakteriyel enfeksiyonu sınırlandırmak ve kök kanal dolgu maddelerinin taşmasını engellemek için sert doku benzeri apikal tıkacın oluşması için apeksifikasyon tedavisi uygulanmaktadır. ${ }^{5}$

Geleneksel olarak, apikal kapanmayı uyarmak için kalsiyum hidroksit ile apeksifikasyon işlemi uygulanır. ${ }^{6}$ Kalsiyum hidroksit ile apeksifikasyon tekniğinin klinik başarısına rağmen; tedavi süresinin değişkenliği, randevu ve alınan radyografi sayısının çokluğu, hasta takibinin güç olması ertelenen tedaviler ve uzun süre kalsiyum hidroksit kullanılmasına bağlı olarak gelişen kök kırığı riskinin ve koronal mikrosızıntının artması gibi pek çok dezavantajı bulunmaktadır. ${ }^{7}$

Birçok araştırmacı tek seans apeksifikasyon tedavisinde mineral trioksit aggregat'ın (MTA) kullanımasının gerekliliğini ve apeksi açık vital olmayan daimi dişlerin tedavisinde kalsiyum hidroksite alternatif olarak önerilen en umut verici materyalin MTA olduğunu söylemektedirler. ${ }^{8-10}$

MTA, apikal bölgede güçlü fiziksel, kimyasal ve klinik özellikler sergilemesi, bakteriyostatik olması, iyi bir tıkaç oluşturması, boyutsal stabilite, radyoopasite, biyouyumluluk ve sızdırmazlık gibi özellikleri nedeniyle tek seanslı apeksifikasyon tekniğinde en çok tercih edilen materyaldir. ${ }^{11}$

Her ne kadar MTA doku uyumu yüksek bir materyal olsa da kanal içinde kullanılan diğer materyaller gibi MTA'nın da kök kanalı sınırlarında kalması önerilir. ${ }^{12}$ İnternal matrix kullanımıyla dolgu veya tamir materyallerinin periapikal bölgeye taşması engellenir, tamir materyalinin sızıntısı azalır ve periodontal dokular korunmuş olur. ${ }^{13}$

Endodontik materyallerin mikrosızıntı değerlendirme yöntemleri; boya sızıntı tekniği, bakteri sızıntı tekniği, sıkıştırılmış hava tekniği, elektrokimyasal teknik, radyoizotop tekniği, sıvı filtrasyon tekniğidir. ${ }^{14}$ 15 Sıvı filtrasyon tekniğin avantajları; diğer sızıntı tekniklerinden farklı olarak örneklerin zarar görmediği için yeniden kullanılabilmesi ve sistemde pozitif basınç kullanılarak hapsedilmiş hava veya sıvının neden olabileceği sorunların önlenmesidir. ${ }^{16,17}$

Bu çalışmada, farklı apikal çaplara sahip (1mm ve $1.4 \mathrm{~mm}$ ) immatur dişlere ortograt ve retrograt yollarla, farklı uygulama teknikleri kullanılarak yerleştirdiğimiz MTA'nın apikal sızıntılarının bilgisayarlı sıvı filtrasyon tekniği ile belirlenmesi amaçlanmıştır.

\section{MATERYAL METOD}

Çalışmada kullanmak için toplam 100 adet kırık, çatlak, çürük ve eksternal rezorbsiyon içermeyen kök oluşumu tamamlanmış üst çene keser dişler seçildi. Örnek dişlerde standardizasyonu sağlamak için diş boyu $22 \mathrm{~mm}$ - $24 \mathrm{~mm}$ olanlar kullanıldı. Kullanılacak dişler dezenfeksiyon için \%5 lik NaOCl (Sultan Healthcare Inc., Englewood, ABD)içeren solüsyon içersinde 1 saat boyunca bekletildikten sonra deney süresine kadar bekletilmek üzere salin içeren sölüsyona aktarıldı.

Dişlerin kronları mine-sement sınırı hizasından herbiri $15 \mathrm{~mm}$ olan standart kökler elde edilecek şekilde elmas frezler yardımıyla uzaklaştırıldı. Gerçek kök kanal uzunluğu 15 numara $\mathrm{K}$ tipi kanal eğesi kök ucundan görünene kadar ilerletilmesi suretiyle belirlendi. Çalışma uzunluğu kök kanal uzunluğundan $1 \mathrm{~mm}$ kısa olacak şekilde belirlendi. Kanal preparasyonu, Gates glidden frezleri ile 6 numaradan 1 numaraya kadar ters sırayla crown down tekniği kullanılarak, 1 numaralı Gates glidden frez apikal foramenden çıkana kadar yapıldı. Her bir farklı numara alet değişiminden sonra \%1'lik sodyum hipoklorit solüsyonuyla (Sultan Health-care Inc., Englewood, ABD) kanallar yıkandı. Preparasyonu biten dişlerin kök kanalları son olarak serum fizyoljik solüsyonuyla yıkanıp \#80 paper pointle kanallar kurulandı. Daha sonra apikal deltaların uzaklaştırılması ve kök uzunluğu standardize etmek için apikal 3 mm'lik kök ucu kısmı elmas frez yardımıyla kesilerek standart boyutlarda diş kökleri elde edildi. Daha sonra örnekler mikrosızıntı deneyi için rastgele bir şekilde farklı apikal açıklıklık oluşturmak için 2 deney grubuna ayrıldı $(n=50)$.

GRUP 1 de açık apeksli bir dişi simüle etmek amacıyla apikal foramen çapı $1 \mathrm{~mm}$ olacak şekilde 0.10

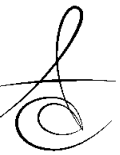


taperlı 40 numara Race Ni-Ti aletleriyle (FKG, LaChaux De Fonds, İsviçre) kök apeksi retrograd olarak genişletildi. Apikal genişliğin $1 \mathrm{~mm}$ olmasını sağlamak için eğenin çalışma uzunluğu $6 \mathrm{~mm}$ olarak sabitlendi $(D=6 \mathrm{~mm})^{18}$. Bu gruptaki 50 adet diş her biri 10 adet dişten oluşacak şekilde 5 alt gruba ayrıldı.

GRUP 1A da üretici firmanın talimatları doğrultusunda karıştırılan MTA apikalde tam bir kapatma sağlayacak şekilde MAP sistemi (Micro Apical Placement) (Dentsply De Trey, Konstanz, Almanya) aracılığıyla apikal $4 \mathrm{~mm}$ alana ortograd olarak yerleştirildi. MTA $4 \mathrm{~mm}$ kalınlığında olana kadar schilder pluggerları aracılığıyla kondanse edildi. Salin solüsyonuyla ıslatılmış paper pointler MTA'nın sertleşmesini sağlamak amacıyla 24 saat süreyle kanal içinde bekletildi. Kanal ağızları paper pointlerin yerleştirilmesini takiben geçici dolgu maddesi (Kavit, 3M ESPE, Seefeld, Almanya)ile kapatıldı.

GRUP 1B da üretici firmanın talimatları doğrultusunda karıştırılan MTA apikalde tam bir kapatma sağlayacak şekilde MAP sistemi aracılığıyla apikal 2 $\mathrm{mm}$ alana ortograd olarak yerleştirildi. MTA $2 \mathrm{~mm}$ kalınlığında olana kadar schilder pluggerları aracılığıyla kondanse edildi. Salin solüsyonuyla ıslatılmış paper pointler MTA'nın sertleşmesini sağlamak amacıyla 24 saat süreyle bekletildi. Kanal ağızları paper pointlerin yerleştirilmesini takiben geçici dolgu maddesi kavit ile kapatıldı. Apikale yerleştirilen MTA'nın pluggerlar aracllı̆yla sertleştiği teyit edildikten sonra önceden yerleştirilmiş $2 \mathrm{~mm}$ kalınlığındaki MTA üzerine önceden anlatıldığı gibi 2mm kalınlığında tekrar MTA yerleştirildi. Islatılmış paper pointler 24 saat süreyle kanal içerisinde bekletildi ve kanal girişleri kavit ile dolduruldu.

Grup 1C da internal matrix olarak sentetik kemik grefti (Suprabone, BMT Calsıs Sağlık Teknolojileri, Ankara, Türkiye) üretici firmanın talimatları doğrultusunda karıştırılıp kendi enjektörü aracılığıyla kök apeksinden taşmayacak şekilde $2 \mathrm{~mm}$ kalınlığında ortagrad olarak yerleştirildi. Daha sonra macun formuna gelmeden el pluggerı aracılığıla apikal sonlanımı tamamen kapatmak ve MTA için yeterli direnç elde edilmesi için kondanse edildi. MTAnın internal matrix üzerine uygulanması Grup1A da anlatıldığı gibi gerçekleştirildi.

GRUP 1D da apikal bölgeye yerleştirilecek MTA'ya barier oluşturmak amacıyla kanallar obtura sistemi kullanılarak termoplastize edilmiş güta-perka
(Bee-Fill, VDW, Münih, Almanya) ile doldurularak daha sonra apikal $4 \mathrm{~mm}$ alandaki güta perka ısıtılmış ekskavatör aracılığıyla kanaldan uzaklaştırıldı. MTA apikalde tam bir kapatma sağlayacak şekilde apikal 4mm alana retrograd olarak yerleştirildi. Salin solüsyonuyla ıslatılmış steril tamponlar MTAnın sertleşmesini sağlamak amacıyla 24 saat süreyle MTA yüzeyine temas edecek şekilde bekletildi.

GRUP 2 de açık apeksli bir dişi simüle etmek amacıyla dişler apikal foramen çapı $1.4 \mathrm{~mm}$ olacak şekilde 0.10 taperlı 40 numara race $\mathrm{Ni}$-Ti aletleriyle kesme boyutunda kök apeksi retrograd olarak genişletildi. Apikal genişliğin $1.4 \mathrm{~mm}$ olmasını sağlamak için eğenin çalışma uzunluğu $10 \mathrm{~mm}$ olarak sabitlendi $(D=10 \mathrm{~mm}) .10$ adet diş içeren 5 alt grup $(2 A, 2 B$, 2C,2D) grup $1^{\prime}$ in alt gruplarındaki aynı prosedürler uygulanarak hazırlandı.

Grup1D ve Grup2D dışındaki tüm gruplarda MTA'nın sertleştiği teyit edildikten sonra kanallar ortagrad olarak termoplastik gütaperka (Bee-Fill, VDW, Münih, Almanya) ve Ah-plus kanal patıyla (Dentsply De Trey, Konstanz, Almanya) doldurulup kanal girişleri cam iyonomer siman ile kapatıldı.

\section{Pozitif Kontrol:}

Grup 1 ve Grup 2'de anlatıldığı gibi hazırlanan örnek dişler yalnızca AH plus ve termoplastik gütaperka ile dolduruldu. $(n=5)$

\section{Negatif kontrol:}

Grup 1 ve Grup 2'de anlatıldığı gibi hazırlanan örnek dişler her gruptan birer örnek olacak şekilde seçilen dişlere MTA retrograd olarak $4 \mathrm{~mm}$ kalınlığında yerleştirildi. $(n=5)$

Hazırlanan tüm örneklerin kök yüzeyleri apikal 4 mm'lik kısmı hariç tırnak cilası ile iki tabaka halinde kaplandı. Negatif kontrol grubundaki örneklerin ise tüm yüzeylerine iki tabaka halinde tırnak cilası uygulandı.

Grupların oluşturulmasından sonra örneklerin hepsi $37^{\circ} \mathrm{C}$ etüvde \% 100 nemli ortamda 7 gün boyunca bekletildi.

\section{Mikrosızıntı Deneyi}

Çalışmamızda kök ucu dolgu materyali ile diş yüzeyi arasından geçen sıvı miktarı, apikal mikrosızıntı olarak kabul edildi. Sızıntı ölçümleri, Selçuk Üniversitesi Diş Hekimliği Fakültesi Laboratuvarında bulunan bilgisayarlı sıvı filtrasyon cihazı kullanılarak yapıldı.

İncelenecek her bir apikal kök parçası öncelikle plastik bir boru ve metal bağlayıc ile 18 gauge'luk

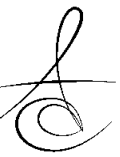


paslanmaz çelik tüpe bağlandı. Çalışmada sıvının filtrasyonu sonucu oluşan birim zamandaki hareketini ölçmek için Oruçoğlu ve ark. nın kullandığı metod uygulandı. ${ }^{19}$ Çalışmada her bir örnekteki sıvı hareketi ölçümleri 15 saniye aralıklarla 8 kez tekrarlandı ve cam mikropipet içerisindeki hava kabarcığının hareket miktarı hesaplandı. Sızıntı miktarı $\mu \mathrm{l} /\left(\mathrm{dk} * \mathrm{cmH}_{2} \mathrm{O} *\right.$ $\mathrm{cm}^{2}$ ) cinsinden belirlendi. Verilerin analizi SPSS 20 programında ANOVA ve post hoc analizi kullanılarak yapıldı.

\section{BULGULAR}

Apikal sızıntı deneylerine ait bulgular Tablo 1'de gösterilmiştir. En az sızıntı internal matrix in $1 \mathrm{~mm}$ genişlikte ortograt uygulanan grupta görüldü. En fazla sızıntı ise; $1.4 \mathrm{~mm}$ açıklığa sahip dişlerde retrograt uygulamada gözlendi. Grup $1 C$ ve $2 D$ hariç diğer gruplar arasında istatistiksel olarak fark yoktur. MTA'nın internal matrix ile birlikte kullanıldığı gruplarda ve MTA'nın iki aşamalı yerleştirildiği gruplarda sızıntı miktarı MTA'nın tek seferde yerleştirildiği gruplardan daha azdır.

Tablo 1. Deneysel ve kontrol grupları için ortalama sızınt miktarı $\mu \mathrm{l} /\left(\mathrm{dk} * \mathrm{cmH}_{2} \mathrm{O} * \mathrm{~cm}^{2}\right)$ ve standart sapma değerleri

\begin{tabular}{|l|l|l|}
\hline Gruplar & Ort. & SD \\
\hline Grup 1A & $0.235 \times 10^{-4 a \mathrm{c}}$ & $0.062 \times 10^{-4}$ \\
\hline Grup 1B & $0.202 \times 10^{-4 \mathrm{bc}}$ & $0.069 \times 10^{-4}$ \\
\hline Grup 1C & $0.142 \times 10^{-4 \mathrm{bce}}$ & $0.142 \times 10^{-4}$ \\
\hline Grup 1D & $0.244 \times 10^{-4 \mathrm{ac}}$ & $0.057 \times 10^{-4}$ \\
\hline Grup 2A & $0.246 \times 10^{-4 \mathrm{ac}}$ & $0.074 \times 10^{-4}$ \\
\hline Grup 2B & $0.228 \times 10^{-4 \mathrm{bc}}$ & $0.068 \times 10^{-4}$ \\
\hline Grup 2C & $0.187 \times 10^{-4 \mathrm{bce}}$ & $0.076 \times 10^{-4}$ \\
\hline Grup 2D & $0.367 \times 10^{-4 \mathrm{a}}$ & $0.141 \times 10^{-4}$ \\
\hline Pozitif Kontrol & $1.537 \times 10^{-4 \mathrm{~d}}$ & $0,123 \times 10^{-4}$ \\
\hline Negatif Kontrol & $0.0 \times 10^{-4 \mathrm{e}}$ & $0.0 \times 10^{-4}$ \\
\hline
\end{tabular}

Farklı üst karakterler " (a-e) " gruplar arasında istatistiksel farkın olduğunu $(P<0.05)$, aynı üst karakterler ise gruplar arasında bir fark olmadığını göstermektedir $(P>0.05)$.

\section{TARTIŞMA}

İnce ve kırımaya yatkın dentin duvarlarına sahip apeksi açık immatür dişlerin endodontik tedavisinde köklerin kırılma direncini artırmaya yönelik tedavilerin yapılması, bu tip dişlerin prognozu açısından önemlidir. ${ }^{20}{ }^{21} \mathrm{Ca}(\mathrm{OH})_{2}$ yerine MTA'nın tercih edildiği bir çalışmada, apeksi açık dişlerin tedavisinde MTA'nın, $\mathrm{Ca}(\mathrm{OH})_{2}$ kadar etkili bir materyal olduğu bulunmuştur. ${ }^{22}$
Bazı araştırmacılar apikal tıkaç olarak kullanılan MTA'nın, yerleştirme kalınlığının sızıntıyı etkilediğini ileri sürmüşlerdir. ${ }^{23}$ Giuliani ve ark. ${ }^{24}$, apeksifikasyon tedavisinde en az MTA yerleştirme kalınlığının $4 \mathrm{~mm}$ olması gerektiğini önermektedirler. Bu yüzden biz de çalışmamızda klinik koşulları taklit etmek için apikal dolgu malzemesi olarak $4 \mathrm{~mm}$ kalınlığında MTA kullandık.

Bazı araştırmacılar; retrograd uygulama tekniğinin başarısının ortograd uygulama tekniği ile olumsuz yönde etkilenebileceğini savunurken ${ }^{25}$; bazı araştırmacılar ise retrograd dolgu maddesi olarak kullanıldığında MTA'nın iyi bir örtücülüğe sahip olduğunu bildirmişlerdir. ${ }^{26}$ Hachmeister ve ark. ${ }^{26}$, kontrol grubunda yer alan MTA retrograd dolgularının \%20'sine kıyasla, MTA ortograd dolgularının \%100'ünün 70. günde bakteriyel penetrasyon gösterdiğini bulmuşlardır. Yazarlar, gözlemlenen sızıntının nedeninin MTA olmadığını, kanal içi uygulama tekniğinin bu sonuca yol açtığını öne sürmüşlerdir. ${ }^{26}$

Retrograd uygulama sırasında MTA, kök ucunda prepare edilen alanda bir matriks ya da gutta-perka konları üzerine kondanse edilerek yerleştirilirken ortograd uygulama sırasında böyle bir direnç söz konusu olmadığından daha fazla teknik hassasiyet gerektirmektedir. Kondensasyon, açık apeksin direncinin minimal olmasına bağlı olarak sınırlı şekilde mümkündür.

İmmature dişlerin tedavi zorluklarından birisi de kök kanal dolgusunu sınılayacak apikal stopun olmamasıdır. Apikal stopun olmayışı ve dolgu materyallerinin apikal bölgeye taşması apikal sızıntı ile sonuçlanır. ${ }^{27}$

MTA'nın kanal adaptasyonu ve sızıntısıyla ilgili birçok çalışma yapılmıştır. ${ }^{28-30} \mathrm{Bu}$ çalışmaların bazılarında ultrasonik uygulanmasının MTA'yı elle göndermeye oranla daha iyi sonuçları olduğunu gösteren çalışmalar olmasına rağmen bunun tersine sonuçları gösteren çalışmalarda mevcuttur. ${ }^{28-30} \mathrm{Bu}$ yüzden MTAnın ortograd yolla kanal içerisine gönderilmesinde ultrasonik yolun tercih edilmesine yönelik genel bir ortak karar hakim değildir. Bu çalışmada MTA, manuel olarak uygulandı.

Klinik açıdan bakıldığında MTA, immatür dişlerin tedavisinde benzersiz bir avantaja sahiptir. Çünkü; doku sıvılarının varlığı yada kanal içerisine eksüdasyonu bu tarz vakalarda sıklıkla görülen bir problemdir. ${ }^{31}$ MTA, nem varlığında sertleşebilir ve apikal bariyer olarak kullanıldığında hücrelerin sert doku oluş-

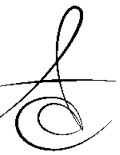


turan hücrelere diferansiyasyonunu sitümüle ederek sert doku matriksinin oluşumunu sağlar. ${ }^{32}$ Her ne kadar MTA'nın apexten periapikal dokulara taşması nispeten güvenli yada yararlı olsa bile malzemenin kontrolü tavsiye edilmektedir. ${ }^{10,33}$

Ik defa Lemon ${ }^{34}$, kök perforasyonlarının tamirinde internal matriks konseptini tamir materyallerinin aşırı taşmalarını sınırlamak amacıyla kullanılmasını savunmuştur. İnternal matrix için kullanılan malzemelerin amalgam gibi kondensasyon kuvveti gerektirmeyen MTA ve IRM gibi materyallerle birlikte kullanılması uygun görülmüştür. ${ }^{34}$ Kalsiyum sülfat, trikalsiyum fosfat, kollojen, dondurulmuş-kurutulmuş demineralize kemik ya da hidroksilapatit gibi rezorbe olabilen bariyerlerin kullanılması MTA'nın yerleştirme zorluğunun giderilmesinde ve taşkın dolgunun önlenmesinde yardımcı olabilmektedir. ${ }^{35}$ Biz de çalışmamızda $\beta$ trikalsiyum fosfat içerikli macun formunda sertleşmeyen, rezorbe olabilen kemik greftini MTA kullanımlarında apikal ekstrüzyonu önlemek için bariyer olarak kullanmayı uygun bulduk.

Hashem ve Hassanien ${ }^{36}$ ise nem kontrolünün sağlanmasıyla MTA'nın daha iyi bir sızdırmazlık ve adaptasyon oluşturduğunu belirtmişlerdir. Ancak Shabahang ve ark. ${ }^{37 \prime n ı n ~ y a p m ı s ̧ ~ o l d u k l a r ı ~ h a y v a n ~ c ̧ a l ı s ̧-~}$ masında rezorbe olabilen kollojenin MTA ile periapikal dokular arasında teması engellediği için apikal sert doku bariyerinin oluşmadığını ortaya koymuşlardır.

Yapılan çalışmada internal matriks olarak kullanılan $\beta$ trikalsiyum fosfat gruplarının hiçbirinde MTA'nın apikal bölgeye taştığı gözlenmemiştir. Yinede sert doku grefti olan $\beta$ trikalsiyum fosfat diğer rezorbe olabilen matriksler gibi baskı dirençlerine dayanım göstermediğinden MTA'nın ortograd olarak kanala yerleştirilmesinde ve kondansasyonunda minimum basınç uygulanarak taşmanın oluşmaması için azami önem gösterilmiştir. İnternal matriks konseptinin MTA'nın uygulanabilmesini kolaylaştırdığı gözlense de basınç karşısında direnç gösterememeleri en önemli eksiklikleri arasındadır.

Çalışma sonuçlarımıza göre; en az sızıntı internal matrix ile MTA'nın 1mm genişlikte uygulandığı grupta görülmüştür. En fazla sızıntı ise; retrograt 1.4 grubunda bulunmuştur. $1 \mathrm{C}$ ve $2 \mathrm{D}$ grupları hariç diğer gruplar arasında istatistiksel olarak bir fark bulunmamıştır. Ancak MTA'nın internal matrix ile birlikte kullanıldığı gruplarda ve MTA'nın iki aşamalı yerleştirildiği gruplarda sızıntı miktarı MTA'nın tek seferde yerleștirildiği gruplardan daha azdır.

Sıvı filtrasyon tekniği, etkili bir sızdırmazlık için kök ucu dolgu materyallerinin etkinliğini ölçen kliniğe en uygun metottur. ${ }^{38}$ Bu sebeple biz de çalışmamızda, yöntemin objektif ve nicel sonuçlar vermesi, güvenilirliğinin yüksek olması nedeniyle bilgisayarlı sıvı filtrasyon tekniğini tercih ettik.

Taneja ve ark. ${ }^{39}$ yaptıkları çalışmada, internal matrix uygulamasının MTA'nın sızıntısını, tek başına ugulanan gruba kıyasla önemli ölçüde azalttığını bulmuşlardır. Sunulan çalışmada da internal matrix uygulamasının MTA'nın sızıntısını azaltan bir teknik olduğu gözlenmiştir.

Moradi ve ark. ${ }^{40}$ 'nın yaptıkları bakteriyel sızıntı çalışmasında; geleneksel olarak retrograd olarak yerleştirilen MTA ile ortograd yerleştirilen MTA arasında apikal sızıntıları arasında istatistiksel bir fark bulunamamıştır. Bu sonuç, bizim çalışma sonuçlarımızla benzerdir.

MTA, dentin yüzeyine bağlanmamasına rağmen, MTA'dan salınan kalsiyum ve hidroksil iyonları ile fosfat içeren vücut sıvıları arasındaki etkileşim, apatit gibi ara yüzey kaplama maddelerinin oluşumuyla sonuçlanır. ${ }^{41} \mathrm{Bu}$ maddeler, materyalin sertleşme fazı sırasında oluşan büzülmenin neden olduğu boşlukları doldurur ve MTA'nın ortograd uygulanması sırasında kök kanal duvarları ve MTA arasında sürtünmenin artmasını sağlar. ${ }^{42}$ Bu bilgiler ışığında MTA'nın ortograd uygulanması, MTA ile kanal duvarları arasında boşlukları azaltır. $\mathrm{Bu}$ da çalışmamızın ortograd uygulanan gruplarında sızıntının neden az olduğunu açıklamaktadır.

Khalilak ve ark. ${ }^{18}$, MTA'nın tek ve iki basamakta yerleştirilmesini farklı apikal genişliğe sahip kanallarda (1mm ve $1.4 \mathrm{~mm}$ ) bakteriyel sızıntı modeliyle değerlendirmişlerdir. Çalışma sonuçlarına göre; farklı apikal genişliğe sahip örnekler arasında fark bulunmamıştır, MTA'nın yerleştirilirken tek veya iki basamaklı uygulamalarında da sonuç aynıdır. ${ }^{18}$ Al-Kahtani ve ark. ${ }^{43}$ da yaptıkları benzer çalışma da Khaliak ve ark. ${ }^{18}$ ve bizim çalışma sonuçlarımızı desteklemektedir.

\section{SONUÇ}

Çalışmamızda uyguladığımız ortograd prosedürde internal matrix ile birlikte uygulandığında apikal sızıntı değerleri daha azdır. Klinik olarak bu metodun tercih edildiği durumlarda, cerrahi uygulama sayıları azaltılabilir ve daha az invaziv uygulamalarla tedaviler

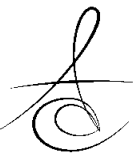


yapılabilir. Ayrıca; MTA'ya bariyer olarak kemik greftleri kullanılabilir. Yine de rezorbe olabilen materyallerin, MTA'nın fiziksel, kimyasal ve biyolojik özellikleri üzerine etkisinin değerlendirileceği daha ileri çalışmalara ihtiyaç vardır.

Teşekkürr: Bu çalışma Gaziosmanpaşa Üniversitesi Bilimsel Araştırma Projeleri Komisyonu tarafından desteklenmiştir. (Proje no : 2013/21).

\section{KAYNAKLAR}

1. D'Arcangelo C, D'Amario $M$. Use of MTA for orthograde obturation of nonvital teeth with open apices: report of two cases. Oral Surg Oral Med Oral Pathol Oral Radiol Endod 2007;104: 98-101.

2. Simon S, Rilliard F, Berdal A, Machtou P. The use of mineral trioxide aggregate in one-visit apexification treatment: a prospective study. Int Endod J 2007; 40: 186-97.

3. Soares J, Santos S, Cesar C, Silva P, Sá M, Silveira $F$, Nunes $E$. Calcium hydroxide induced apexification with apical root development: a clinical case report. Int Endod J 2008; 41: 710-9.

4. Morse DR, O'Larnic J, Yesilsoy C. Apexification: review of the literature. Quintessence Int, 1990; 21: 589-98.

5. Estrela C, Bammann LL, Pimenta FC, Pecora JD. Control of microorganisms in vitro by calcium hydroxide pastes. Int Endod J, 2001,34: 341-5.

6. Frank AL. Therapy for the divergent pulpless tooth by continued apical formation. J Am Dent Assoc 1966; 72:87-93.

7. Camilleri J, Pitt Ford TR. Mineral trioxide aggregate: a review of the constituents and biological properties of the material. Int Endod J 2006; 39: 747-54.

8. Hayashi M, Shimizu A, Ebisu S. MTA for obturation of mandibular central incisors with open apices: case report. J Endod, 2004,30: 120-2.

9. Stefopoulos S, Tsatsas DV, Kerezoudis NP, Eliades G. Comparative in vitro study of the sealing efficiency of white vs grey ProRoot mineral trioxide aggregate formulas as apical barriers. Dent Traumatol 2008; 24: 207-13.

10. Felippe WT, Felippe MC, Rocha MJ. The effect of mineral trioxide aggregate on the apexification and periapical healing of teeth with incomplete root formation. Int Endod J 2006; 39: 2-9.
11. Torabinejad M, Chivian N. Clinical applications of mineral trioxide aggregate. J Endod 1999; 25: 197205.

12. Holland R, Mazuqueli L, de Souza V, Murata SS, Dezan Júnior $E$, Suzuki $P$. Influence of the type of vehicle and limit of obturation on apical and periapical tissue response in dogs' teeth after root canal filling with mineral trioxide aggregate. J Endod 2007; 33: 693-7.

13. Sood R, Kumar Hans M, Shetty S. Apical barrier technique with mineral trioxide aggregate using internal matrix: a case report. Compend Contin Educ Dent 2012; 33: 88-90.

14. Cobankara FK, Orucoglu H, Sengun A, Belli S. The quantitative evaluation of apical sealing of four endodontic sealers. J Endod 2006; 32: 66-8.

15. da Silva Neto UX, de Moraes IG, Westphalen VP, et al. Leakage of 4 resin-based root-canal sealers used with a single-cone technique. Oral Surg Oral Med Oral Pathol Oral Radiol Endod 2007;104:53-7.

16. De Bruyne MA, De Bruyne RJ, Rosiers L, De Moor $\mathrm{RJ}$. Longitudinal study on microleakage of three root-end filling materials by the fluid transport method and by capillary flow porometry. Int Endod J 2005; 382: 129-36.

17. Üstün Y, Dinçer AN, Yıldırım C, Sağsen B, Oruçoğlu $\mathrm{H}$, Aslan B. Güta Perka Konların Kimyasal Dezenfeksiyonunun Apikal Sızıntı Üzerindeki Etkisi. Atatürk Üniv Diş Hek Fak Derg 2013; 21: 187-91.

18. Khalilak Z, Vali T, Danesh F, Vatanpour M. The Effect of One-Step or Two-Step MTA Plug and Tooth Apical Width on Coronal Leakage in Open Apex Teeth. Iran Endod J 2012; 7: 10-4.

19. Orucoglu $H$, Sengun A, Yilmaz N. Apical leakage of resin based root canal sealers with a new computerized fluid filtration meter. J Endod 2005; 31: 886-90.

20. Andreasen JO, Farik B, Munksgaard EC. Long-term calcium hydroxide as a root canal dressing may increase risk of root fracture. Dent Traumatol 2002; 18: 134-7.

21. Wilkinson KL, Beeson TJ, Kirkpatrick TC. Fracture resistance of simulated immature teeth filled with resilon, gutta-percha, or composite. J Endod 2007; 33: 480-3.

22. Pradhan DP, Chawla HS, Gauba K, Goyal A. Comparative evaluation of endodontic management of teeth with unformed apices with

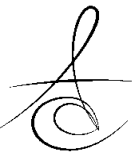


mineral trioxide aggregate and calcium hydroxide. J Dent Child(Chic) 2006; 73: 79-85.

23. de Leimburg ML, Angeretti $A$, Ceruti $P$, Lendini $M$, Pasqualini D, Berutti E. MTA obturation of pulpless teeth with open apices: bacterial leakage as detected by polymerase chain reaction assay. J Endod 2004; 30: 883-6.

24. Giuliani V, Baccetti T, Pace R, Pagavino G. The use of MTA in teeth with necrotic pulps and open apices. Dent Traumatol 2002; 18: 217-21.

25. Pace R, Giuliani V, Pini Prato L, Baccetti T, Pagavino G. Apical plug technique using mineral trioxide aggregate: results from a case series. Int Endod J 2007; 40: 478-84.

26. Hachmeister DR, Schindler WG, Walker WA, 3rd, Thomas DD. The sealing ability and retention characteristics of mineral trioxide aggregate in a model of apexification. J Endod 2002; 28: 386-90.

27. Trope MB, Chivian N, Sigurdsson A. Pathways of the pulp. 9th ed. St Louis: Mosby; 2006. p. 610-49.

28. Lawley GR, Schindler WG, Walker WA, 3rd, Kolodrubetz D. Evaluation of ultrasonically placed MTA and fracture resistance with intracanal composite resin in a model of apexification. J Endod 2004; 30: 167-72.

29. Yeung P, Liewehr FR, Moon PC. A quantitative comparison of the fill density of MTA produced by two placement techniques. J Endod 2006; 32: 4569.

30. Aminoshariae A, Hartwell GR, Moon PC. Placement of mineral trioxide aggregate using two different techniques. J Endod 2003; 29: 679-82.

31. Funteas UR, Wallace JA, Fochtman EW. A comparative analysis of Mineral Trioxide Aggregate and Portland cement. Aust Endod J 2003; 29: 43-4.

32. Chang SW, Oh TS, Lee W, Cheung GS, Kim HC. Long-term observation of the mineral trioxide aggregate extrusion into the periapical lesion: a case series. Int J Oral Sci 2013; 5: 54-7.

33. Tahan E, Celik D, Er K, Tasdemir T. Effect of unintentionally extruded mineral trioxide aggregate in treatment of tooth with periradicular lesion: a case report. J Endod 2010; 36: 760-3.

34. Lemon RR. Nonsurgical repair of perforation defects. Internal matrix concept. Dent Clin North Am 1992; 36: 439-57.

35. Nosrat A, Nekoofar MH, Bolhari B, Dummer PM. Unintentional extrusion of mineral trioxide aggregate: a report of three cases. Int Endod J 2012; 45: 1165-76.

36. Hashem AA, Hassanien EE. ProRoot MTA, MTAAngelus and IRM used to repair large furcation perforations: sealability study. J Endod 2008; 34: 59-61.

37. Shabahang S, Torabinejad M, Boyne PP, Abedi H, McMillan P. A comparative study of root-end induction using osteogenic protein-1, calcium hydroxide, and mineral trioxide aggregate in dogs. J Endod 1999; 25: 1-5.

38. Bates CF, Carnes DL, del Rio CE. Longitudinal sealing ability of mineral trioxide aggregate as a root-end filling material. J Endod 1996; 22: 575-8.

39. Taneja S, Kumari M. Effect of internal matrices of hydroxyapatite and calcium sulfate on the sealing ability of mineral trioxide aggregate and light cured glass ionomer cement. J Conserv Dent 2011; 14: 6-9.

40. Moradi S, Disfani R, Ghazvini K, Lomee M. Sealing Ability of Orthograde MTA and CEM Cement in Apically Resected Roots Using Bacterial Leakage Method. Iran Endod J 2013; 8: 109-3.

41. Bozeman TB, Lemon RR, Eleazer PD. Elemental analysis of crystal precipitate from gray and white MTA. J Endod 2006; 32: 425-8.

42. De-Deus G, Petruccelli V, Gurgel-Filho E, CoutinhoFilho T. MTA versus Portland cement as repair material for furcal perforations: a laboratory study using a polymicrobial leakage model. Int Endod $\mathrm{J}$ 2006; 39: 293-8.

43. Al-Kahtani A, Shostad S, Schifferle R, Bhambhani S. In-vitro evaluation of microleakage of an orthograde apical plug of mineral trioxide aggregate in permanent teeth with simulated immature apices. J Endod 2005; 31: 117-9.

\section{Yazışma Adresi:}

Hüda Melike Bayram

Gaziosmanpaşa Üniversitesi,

Diş Hekimliği Fakültesi,

Endodonti Anabilim Dalı.

Ali Sevki Erek Yerleşkesi,

Tokat. Türkiye.

Tel: +905058598284

Fax: +90 3562124225

mail: melikealaca@yahoo.com 